DIW BERLIN

Discussion

Papers

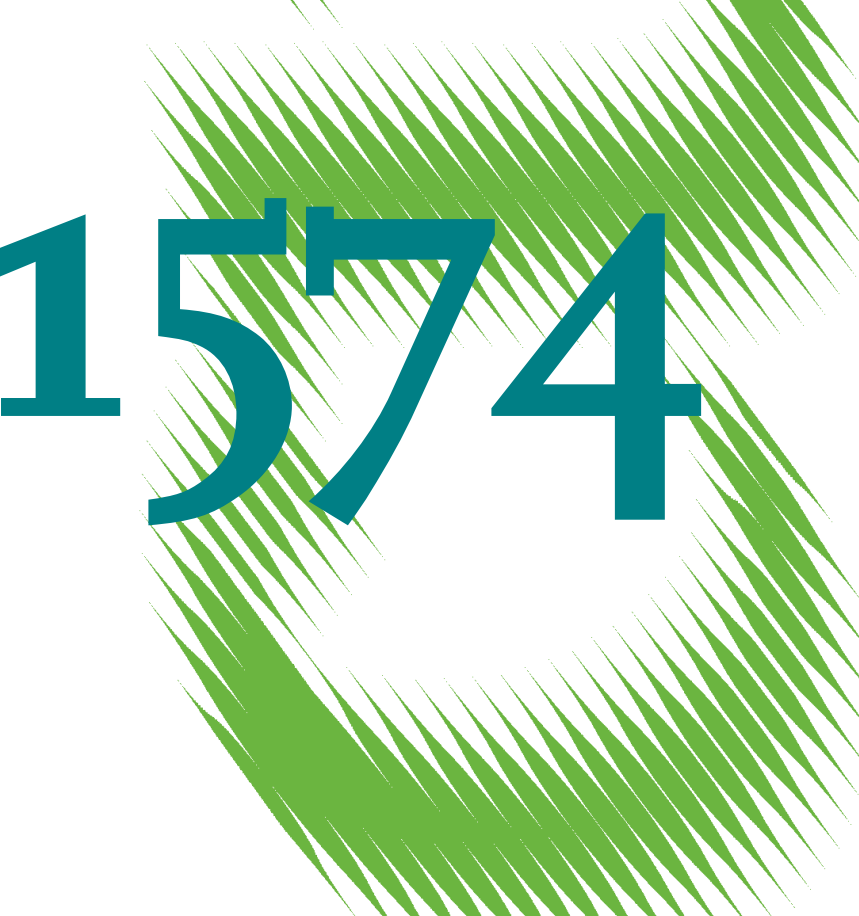

Coordination of Renewable Energy Remuneration Schemes through Information Exchange 
Opinions expressed in this paper are those of the author(s) and do not necessarily reflect views of the institute.

IMPRESSUM

(C) DIW Berlin, 2016

DIW Berlin

German Institute for Economic Research

Mohrenstr. 58

10117 Berlin

Tel. +49 (30) $89789-0$

Fax +49 (30) $89789-200$

http://www.diw.de

ISSN electronic edition 1619-4535

Papers can be downloaded free of charge from the DIW Berlin website:

http://www.diw.de/discussionpapers

Discussion Papers of DIW Berlin are indexed in RePEc and SSRN:

http://ideas.repec.org/s/diw/diwwpp.html

http://www.ssrn.com/link/DIW-Berlin-German-Inst-Econ-Res.html 


\title{
Coordination of Renewable Energy Remuneration Schemes through Information Exchange
}

\author{
Thilo Grau ${ }^{1}$, Karsten Neuhoff ${ }^{2}$
}

2016

\begin{abstract}
The increasing scale and dynamics of the global market for renewable energy technologies has often resulted in unexpected high deployment volumes in EU Member States. These deployment peaks were particularly strong for solar photovoltaic (PV) technologies in countries using feed-in tariff remuneration mechanisms. In this paper, we develop an analytic model to capture the interactions of national remuneration schemes with the global market. The model covers two countries and one global technology market. We calibrate the model for the impact of coordinated tariff adjustments based on the experience with PV in Germany and the UK. We then use the model to measure the impact of different global module supply functions, national installation price reductions, and specific shocks on deployment effectiveness in terms of reaching national or aggregated target corridors for separate and coordinated feed-in tariff adjustment mechanisms. The relevance of the insights for wind energy technologies is evaluated. Based on the results, we discuss the implications for the coordination of remuneration schemes.
\end{abstract}

Keywords: Renewable energy, feed-in tariff, coordinated remuneration schemes

JEL: D78, L94, O3

This work has been co-funded by the Intelligent Energy Europe Programme of the European Union.

\footnotetext{
${ }^{1}$ DIW Berlin, D-10117 Berlin, tgrau@diw.de

${ }^{2}$ DIW Berlin, D-10117 Berlin, kneuhoff@diw.de
} 


\section{Introduction}

The increasing scale and dynamics of the global market for renewable energy technologies has often resulted in unexpected high deployment volumes in EU Member States. These unexpected demand peaks were particularly strong for solar photovoltaics (PV) technologies because of their dynamic cost reductions and short project durations, and often occurred in countries using feed-in tariff remuneration mechanisms. Renewable electricity in Europe has mainly been remunerated through feed-in tariffs, as they provide low investment risks in comparison to quota systems (Held et al., 2014). However, feed-in tariff schemes pose the challenge of setting remuneration levels which are appropriately aligned with technological cost developments.

The EU renewable energy directive (EU Directive, 2009) requests Member States to establish national renewable energy action plans, and provides different cooperation options between Member States. Section 2 discusses different options to coordinate remuneration schemes for renewable energies, and gives an overview on PV deployment, cost development and feed-in tariff adjustment.

If tariff setting across EU Member States will be increasingly coordinated, then an increasing share of global demand will be covered tariffs or quantities set in coordinated mechanisms. In this case it might no longer be suitable to consider the developments of global markets as exogenous. In this paper, we develop a simplified analytic model to assess the interactions between national deployment volumes, global technology markets, and different tariff adjustment mechanisms. Section 3 presents the analytic framework.

The model for the impact of coordinating tariffs for renewable electricity is calibrated based on the experience with PV. Given the limited experience with PV deployment in several EU Member States, the model was not calibrated to reflect the specific situation of each country. Instead, the objective was to capture the main drivers that are relevant for the coordination of remuneration schemes between Member States. Therefore, the model is calibrated based on data for Germany, which is the largest PV market in the world, and the UK, which has been the largest PV market in Europe in 2014. Section 4 presents data and parameter choices.

The results of the analysis are presented in section 5 . We measure the impact of different global module supply functions, national installation prices, and specific shocks on deployment effectiveness in terms of reaching national or aggregated target corridors for separate and coordinated feed-in tariff adjustment mechanisms. As some of the insights that emerged are also applicable to wind energy technologies, we provide a qualitative discussion of the relevance. Section 6 concludes. 


\section{Coordination of remuneration schemes and PV market development}

\subsection{EU renewable energy policies}

The EU renewable energy directive (EU Directive, 2009) defines national targets for the share of energy from renewable sources in gross final energy consumption in 2020 and requests Member States to establish national renewable energy action plans (NREAP) including sectoral targets as well as to set out measures to achieve those targets. Thus, EU Member States define in their national renewable energy action plans individual renewable energy targets, including technology specific renewable electricity targets, and corresponding policy measures.

Feed-in tariffs have been the most common policy instrument in Europe to remunerate renewable electricity generation. The EU Guidelines on State aid for environmental protection and energy require that from 2017 onwards aid for renewable electricity is granted in a competitive bidding process with the exception of installations with less than 1 MW installed electric capacity (EC, 2014). Thus, Member States need to implement tenders for large-scale projects from 2017 onwards, while they can continue to use administratively determined feed-in tariffs to remunerate renewable electricity from plants with up to $1 \mathrm{MW}$ installed capacity.

\section{$2.2 \quad$ Coordination of remuneration schemes}

EU countries are currently individually responsible for the selection, design and implementation of remuneration schemes for renewable energy. However, the EU renewable energy directive provides different cooperation mechanisms between Member States, namely statistical transfers, joint projects and joint support schemes. Klessmann et al. (2014) provide an overview of Member States' progress in implementing these cooperation mechanisms. While policy makers must coordinate their decisions when cooperating on joint projects and joint support schemes, they need to agree on a common policy type in case of joint support schemes (Kitzing et al., 2012). Moreover, the Directive states that "cooperation can also take the form of [...] exchanges of information and [...] other voluntary coordination between all types of support schemes" (EU Directive, 2009).

There are many options to coordinate remuneration schemes across Member States. For instance, remuneration levels or tariff adjustment mechanisms can be fully harmonised across the EU or adapted to regional conditions or national requirements. While EU wide harmonisation of remuneration rules for renewable electricity generation might realise cost saving potentials from clustering installations in beneficial areas (PV in the south, wind turbines in coastal areas), there are additional costs associated with grid extension and long-distance transmission, and different national and local benefits of renewable electricity generation (Lehmann et al., 2012). Moreover, completely harmonised schemes like harmonised tariff levels are difficult to implement, because of large differences in market conditions (resource conditions, differences in installation prices, etc.), and because of information asymmetries across countries. 
Governments can also exchange information to coordinate remuneration schemes, for instance to improve their tariff setting procedures or to calibrate their tariff adjustment mechanisms. National governments normally do not possess comprehensive information about recent international deployment volumes, transparent costs of module production, equipment and installations work, or changes in foreign market or policy frameworks. To coordinate remuneration schemes, countries could exchange information about the following data: deployment, installation costs or prices (installation labour, customer acquisition and system design, permitting, interconnection, inspection), tariff levels, impact of tariffs on installation prices, weather conditions, financing agreements, policy changes, tax frameworks, or administrative barriers. Such information can be exchanged on different timescales, for instance on a monthly or weekly basis, considering necessary time lags to gather the relevant information.

In this paper, we focus on analysing the coordination of feed-in tariffs through information exchange on deployment levels, with a particular focus on photovoltaic technologies. We can differentiate between separate national feed-in tariff setting mechanisms which incorporate recent foreign information, and coordinated tariff adjustment schemes which respond to information across countries.

We analyse the effectiveness of different remuneration schemes, which is an important measure to ensure stable market developments and to avoid collapsing market outcomes (see Figure 1). To evaluate deployment effectiveness, we need to differentiate between effectiveness in terms of reaching national target corridors, and effectiveness with regard to aggregate corridors across countries.

Moreover, coordinated remuneration schemes can be evaluated based on their responsiveness to specific shocks. Such shocks can be different in nature (deployment shocks, price shocks, etc.) and impact (national vs. international, temporarily vs. permanent, similar vs. opposed across countries). Finally, coordinated schemes may help to reduce strategic gaming or market power in smaller countries with large projects or companies.

\subsection{PV deployment and feed-in tariff adjustment}

The global PV market, in comparison to other renewable energy technologies, has shown the strongest technology cost and price reductions, short project durations, and therefore the most dynamic market deployment. This has often resulted in unexpected high deployment volumes in EU Member States. Figure 1 shows historic PV deployment levels in Germany, UK, France, Italy, and Spain. These countries represent the largest PV markets in Europe and together account for $82 \%$ of the European market at the end of 2014. They have used different types of feed-in tariff mechanisms to remunerate PV power generation.

In Germany, annual PV deployment volumes reached around 7.5 GW in both 2011 and 2012, despite numerous previous adjustments to the feed-in tariff mechanism. While Spain experienced strong deployment in 2008, Italy had a strong deployment peak in 2011. Germany is the largest PV market in the world, and the UK has been the largest PV market in Europe in 2014 (REN21, 2015). 


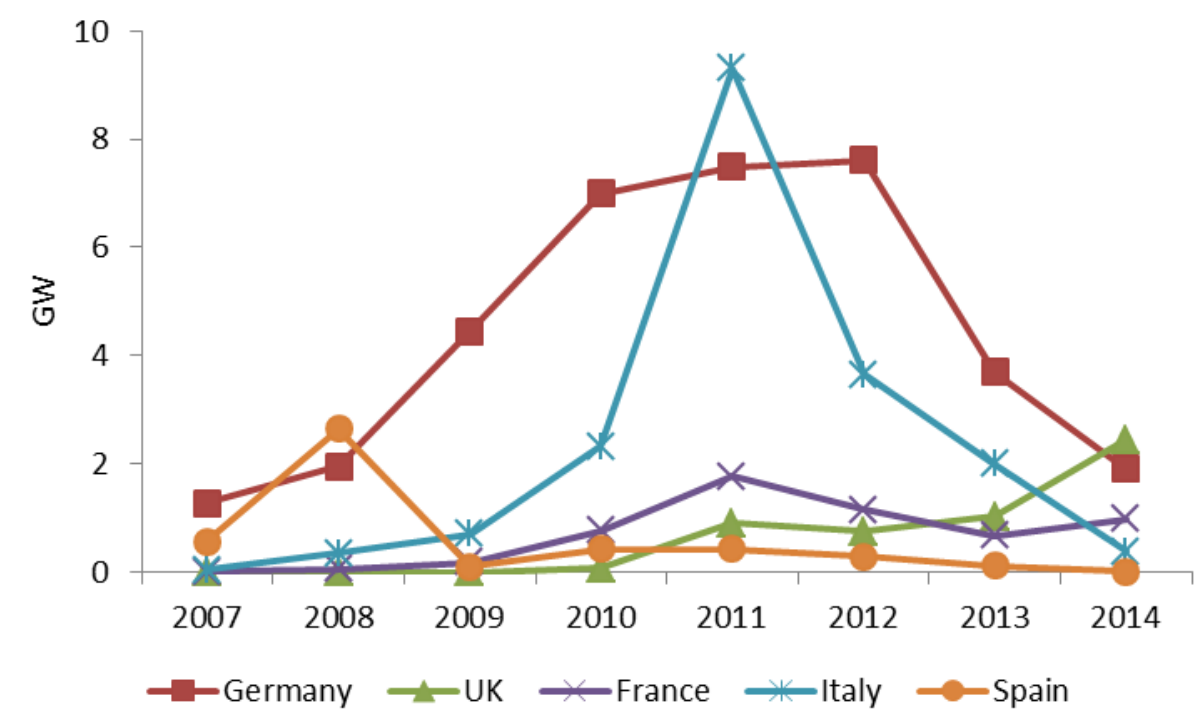

Figure 1: Annual PV deployment for largest EU markets

Data source: I RENA (2015a).

EU Member States apply different methodologies to revise and adjust feed-in tariff levels to technological learning effects: (i) periodic revision and adjustment, (ii) periodical degression, and (iii) capacity dependent tariff adjustment (Held et al., 2014). In this paper, we focus on capacity dependent tariff adjustments for new installations, as this methodology is able to quickly and automatically align tariff levels so as to reach specific deployment corridors. Capacity based tariff adjustments are especially promising for technologies with fast cost reductions and short project development durations, like PV. In this mechanism, the remuneration level for new installations is adjusted regularly by a flexible value which depends on installed capacities in a certain historic period, while existing plants usually receive a constant tariff for a guaranteed period of remuneration. In the case of constant adjustment frequencies across system sizes, investment risks are relatively low for small projects with short development and construction durations.

Both Germany and the UK use capacity dependent tariff adjustment schemes. Figure 2 shows weekly PV deployment for systems up to $50 \mathrm{~kW}$ and corresponding feed-in tariff levels in Germany and the UK between February 2012 and March 2014. 


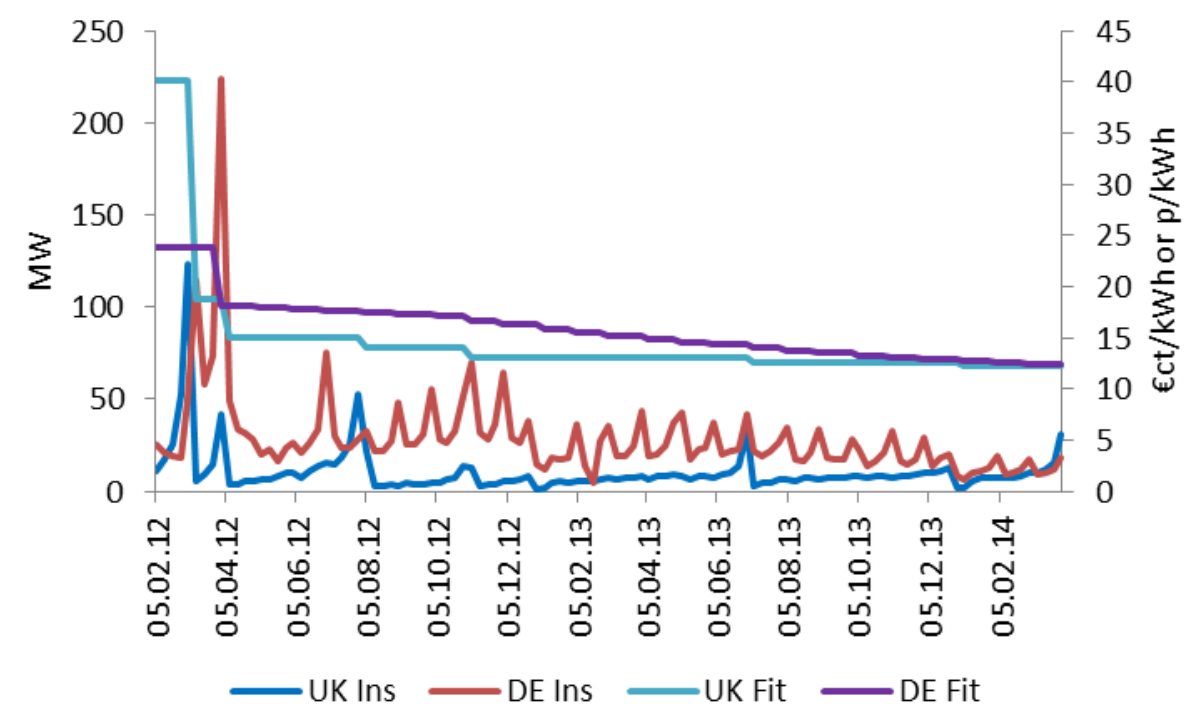

Figure 2: Weekly PV installations and feed-in tariffs for systems up to $50 \mathrm{~kW}$ in Germany and the UK

Data sources: Bundesnetzagentur (2015), DECC (2014a), Ofgem (2014).³.

PV investments are highly responsive to tariff changes (Figure 2). Deployment usually peaks in periods preceding feed-in tariff reductions, as investors still want to receive the higher tariff levels. In both Germany and the UK, we observe the strongest deployment peak just before large tariff reductions. In case of monthly tariff reductions in Germany, installations peak correspondingly on a monthly scale.

\subsection{PV cost and prices}

PV technologies are characterised by high upfront investment cost, no fuel cost, and limited maintenance cost. The prices for installed PV systems cover their costs and margins. The price of a PV system can be separated into the module price and the installation price.

Figure 3 shows PV system prices in 2013 in Germany, the UK, France and Italy. Figure 4 shows weekly system prices for PV installations up to $50 \mathrm{~kW}$ in Germany and the UK between February 2012 and March 2014.

\footnotetext{
${ }^{3}$ German feed-in tariff levels for systems up to $50 \mathrm{~kW}$ are calculated based on average feed-in tariff levels of relevant size categories (sub $30 \mathrm{~kW}$ and sub $100 \mathrm{~kW}$ before April 2012, sub $10 \mathrm{~kW}$ and sub $40 \mathrm{~kW}$ and sub $1 \mathrm{MW}$ from April 2012 onwards). UK feed-in tariff levels for systems up to $50 \mathrm{~kW}$ are calculated based on average feed-in tariff levels of relevant tariff bands $(0-4 \mathrm{~kW}, 4-10 \mathrm{~kW}, 10-50 \mathrm{~kW})$, using middle rates for all tariff bands, and using tariffs for new buildings for tariff band of $4 \mathrm{~kW}$ or less.
} 


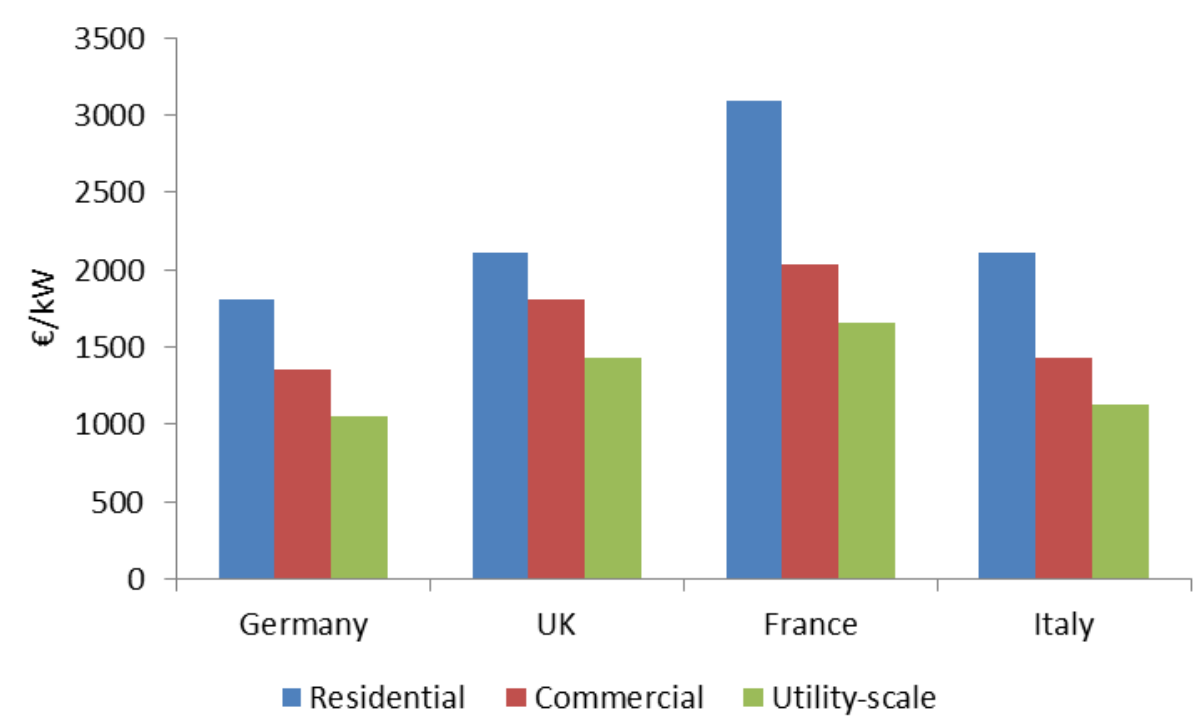

Figure 3: PV system prices in 2013 in selected EU countries

Data source: IEA (2014). Currency exchange rate from oanda.com.

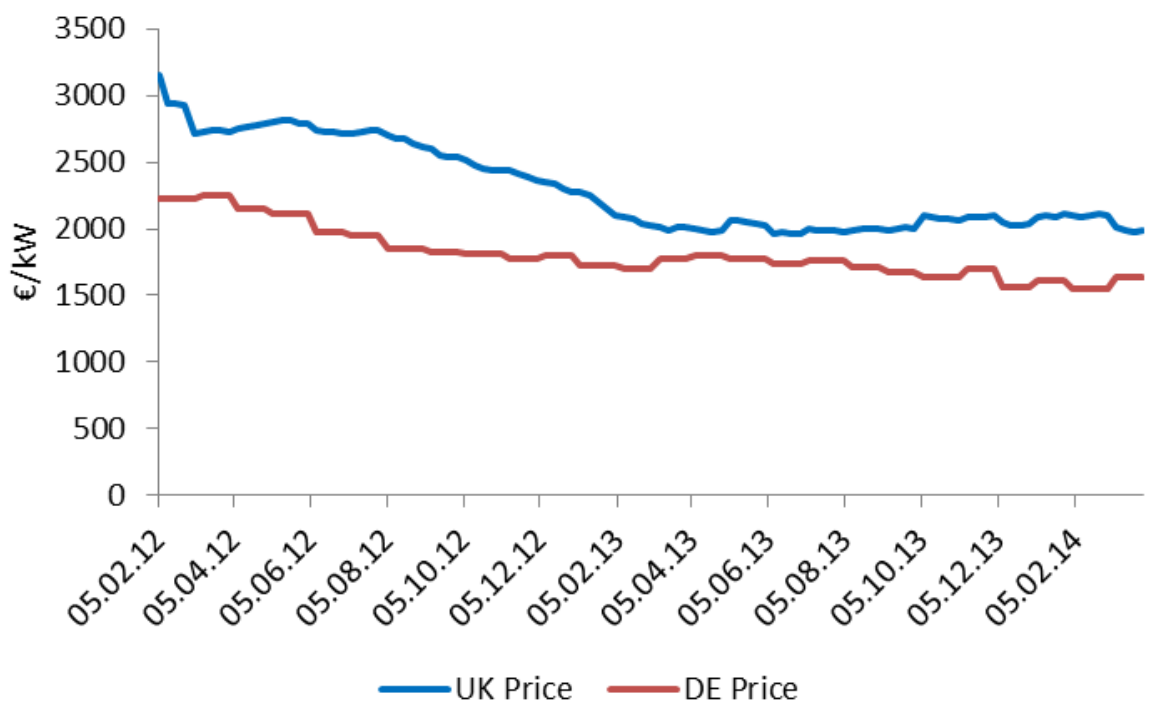

Figure 4: Weekly PV prices for systems up to $50 \mathrm{~kW}$ in Germany and the UK between February 2012 and March 2014

Data sources: DECC (2012), DECC (2014b), Photovoltaik-guide (2014).4.

PV modules tend to be global commodities (IEA, 2014), which can be purchased at similar prices in mature PV markets (Seel et al., 2014). Figure 5 shows prices for crystalline PV modules from Germany and China on the European spot market. While

${ }^{4}$ The German data for system prices up to $50 \mathrm{~kW}$ is based on data for systems up to 100 kW from Photovoltaik-guide (2014) adjusted by a fixed shift factor based on data from IEA (2011). The UK cost data represents the mean cost across relevant size bands (0$4 \mathrm{~kW}, 4-10 \mathrm{~kW}, 10-50 \mathrm{~kW})$. We use historic weekly exchange rates from oanda.com. 
German modules were 35\% more expensive than Chinese modules at the beginning of 2012, prices strongly converged over the last years and reached a minor $2 \%$ price difference in July 2015. Current module prices amount to around $570 € / \mathrm{kW}$.

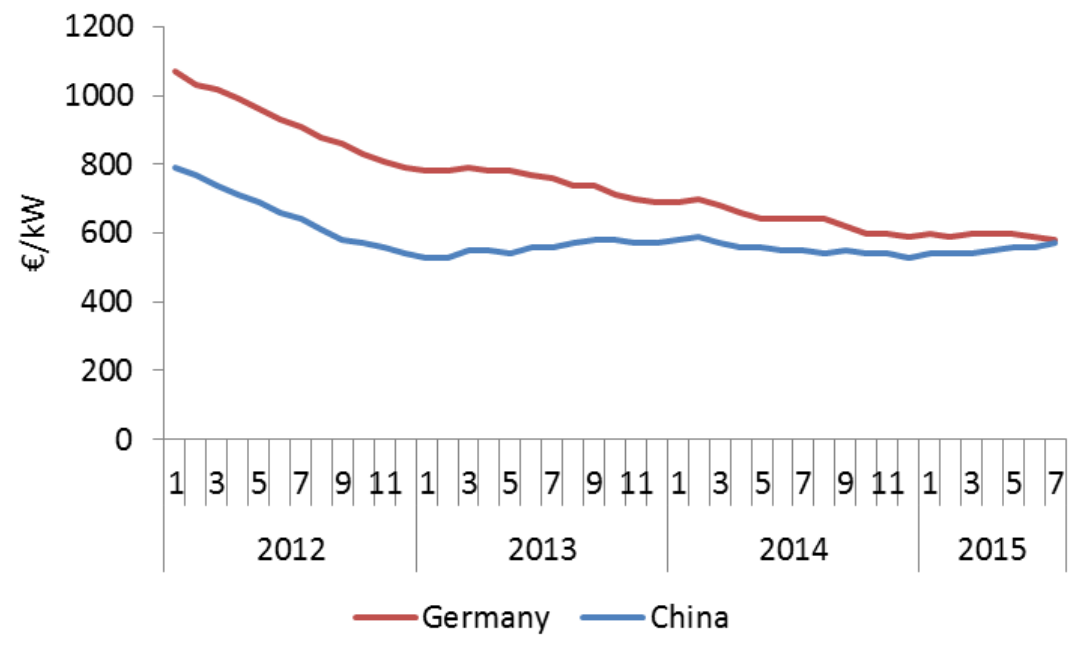

Figure 5: Prices for crystalline PV modules from Germany and China between 2012 and July 2015

Data source: PvXchange (2015). ${ }^{5}$.

Thus, the large PV system price discrepancies between countries for similar system types (see Figure 3) result primarily from differences in national installation prices. The installation price covers the inverter and the balance of system (BOS; including planning, permitting, mounting, grid connection). For current ground-mounted PV systems with 1 MW size in Germany, the module has a $55 \%$ share of the investment cost (Fh ISE, 2015).

Operation and maintenance (O\&M) cost for PV are relatively small in comparison to investment cost (see Table 1), annual O\&M accounts for around 1\% of investment (IEA, 2014).

Table 1: PV operation and maintenance cost

\begin{tabular}{lcccc}
\hline & $\begin{array}{c}\text { Fixed annual O\&M cost } \\
\text { (USD2010/kW) }\end{array}$ & $\begin{array}{c}\text { Variable O\&M cost } \\
\text { (USD2010/MWh) }\end{array}$ \\
\hline Rooftop & 17 & Median & Max & 0 \\
Utility & 12 & 37 & 44 & 0 \\
\hline Sour & 20 & 30 & 0 \\
\hline
\end{tabular}

Source: IPCC (2014)

Due to the dynamic market evolution of PV technologies and the corresponding global module market, a coordinated tariff setting approach has to take into account the global nature of PV module prices.

\footnotetext{
${ }^{5}$ Wholesale average net prices on the European spot market, without value added tax.
} 


\section{Modelling coordinated tariffs for PV}

We develop a simplified analytic model in this chapter to capture the interactions of national remuneration schemes with the global PV module market, and to provide insights on the impact of coordinated tariff setting for renewable energies across EU Member States. This model allows for the analysis of different options to coordinate developments of national feed-in tariff schemes and their relative benefits.

The analytic framework developed in this chapter is based on the basic model of Grau (2014), which simulates national deployment volumes in response to exogenous developments in technology system prices and with different national feed-in tariff adjustment mechanisms. With the perspective of increased coordination of tariff setting across EU Member States, it will no longer be possible to consider the developments of global markets as exogenous, because of the increasing share of demand covered tariffs or quantities set in coordinated mechanisms. Thus, in comparison to Grau (2014), we focus on aggregate demand functions across countries, consider an endogenous global PV module supply function, and account for national installation prices.

\subsection{Demand and supply model}

Demand for PV installations of a representative country $i$ in period $t$ is approximated with a linear demand function

$$
D_{i t}=\alpha_{i} *\left(F_{i t}-p_{M G t}-p_{B o S i t}\right)+\alpha_{0 i}
$$

with global module price $p_{M G}$, national installations price $p_{B O S i}$, the present value of the feed-in tariff $F$, and parameters $a_{i}$ (slope) and $a_{0}$ estimated based on historic data. Project durations between purchase of modules and grid connection are neglected here. Profit levels of PV projects are defined as net present value, taking into account the present value of the feed-in tariff, as well as the module and installation price. As PV operation and maintenance cost are relatively small compared to investment cost (see section 2.4), we neglect them here. The model framework assumes a linear correlation between deployment and profit levels, but could also use alternative functional relationships.

The present value $\mathrm{F}$ of the feed-in tariff is defined according to the equation

$$
F_{i t}=f_{i t} * h_{i} * \sum_{c=0}^{n}\left(1+r_{i}\right)^{-c}
$$

with feed-in tariff $f$, full load hours $h$ per year, $n$ years which the tariff is paid for, and annual interest rate $r$.

The aggregate demand function across countries is then given by the equation

$$
D_{t}=\sum_{i} D_{i t}=\sum_{i}\left\{\alpha_{i}\left(F_{i t}-p_{M G t}-p_{B o S i t}\right)+\alpha_{0 i}\right\}
$$

This demand curve gives the capacity that will be installed at a given module price and conditional on feed-in tariffs and installation prices. 
To regard the developments of global markets as endogenous, we analyse the impact of a global supply function for PV modules on aggregate demand. We consider a standard linear demand and supply model. The linear global supply function for PV systems

$$
S_{t}=s * p_{M G t}+s_{0}
$$

with parameters $s$ and $s_{0}$ describes how much module producers are willing to sell at a given module price.

Market clearing with supply equalling demand, i.e. $D_{t}=S_{t}$, leads to the equilibrium global module price function

$$
p_{M G t}=\frac{\sum_{i}\left(\alpha_{i} F_{i t}-\alpha_{i} p_{B O S i t}+\alpha_{0 i}\right)-s_{0}}{s+\sum_{i} \alpha_{i}}
$$

The aggregate demand function as function of national installation prices is then

$$
D_{t}=\sum_{i}\left(\alpha_{i} F_{i t}-\alpha_{i} p_{B O S i t}+\alpha_{0 i}\right)-\sum_{i} \alpha_{i} \frac{\sum_{i}\left(\alpha_{i} F_{i t}-\alpha_{i} p_{\text {BoSit }}+\alpha_{0 i}\right)-s_{0}}{s+\sum_{i} \alpha_{i}}
$$

If we assume perfect information, we can consider two different tariff setting cases. In the case of separate tariff setting, each country is responsible for individually setting its tariffs. In the case of harmonised tariff setting, the same tariffs are set across countries.

For separate tariff setting across countries i $\varepsilon\{\mathrm{j}, \mathrm{k}\}$ (and with the assumption of perfect information), country $j$ changing tariff $F_{j t}$ leads to

$$
\frac{\partial D_{t}}{\partial F_{j t}}=\alpha_{j} \frac{s}{s+\alpha_{j}+\alpha_{k}}
$$

For the case of harmonised tariff setting with equal remuneration levels $F_{j}=F_{k}=F$ across countries, we get

$$
\frac{\partial D_{t}}{\partial F_{t}}=\left(\alpha_{j}+\alpha_{k}\right) \frac{s}{s+\alpha_{j}+\alpha_{k}}=\frac{\partial D_{t}}{\partial F_{j t}}+\frac{\partial D_{t}}{\partial F_{k t}}
$$

In this case, countries changing their harmonised tariff $F_{t}$ would have the same effect as both countries correspondingly changing their respective separate tariffs $F_{j t}$ and $F_{k t}$. It is important to note that entirely harmonised tariff levels across EU Member States are difficult to implement due to different national market conditions (e.g. different installation prices or resource conditions). 


\subsection{Coordinating tariffs through information exchange}

Given that national governments do not possess comprehensive information about foreign market conditions, we now relax the assumption of perfect information and consider information asymmetries. There are multiple options to design coordinated remuneration schemes which are able to incorporate different data (see section 2.2). We focus our analysis on the coordination of national feed-in tariffs through frequent information exchange on deployment levels.

For separate tariff determination, the feed-in tariff is set according to the equation

$$
f_{i, t+1}=f_{i t} *\left(1-c_{i t}\right)
$$

with degression c being

$$
c_{i t}=\beta_{1} D_{i q}+\beta_{0}
$$

and $D_{\text {iq }}$ being the deployment volume in a specific historic qualification period $q$.

In a model framework with two countries i $\varepsilon\{\mathrm{j}, \mathrm{k}\}$, the coordinated tariff is set according to the function

$$
f_{i, t+1}=f_{i t} *\left(1-\beta_{1}\left(\frac{\sum_{i} D_{i q}}{2}\right)-\beta_{0}\right)
$$

with equal weighting of historic deployment across countries. Optionally, historic deployment could be weighted according to national market shares, or weighted stronger for domestic data than for foreign information.

The model to set coordinated tariffs through information exchange on deployment levels allows for a quantification of the effectiveness of coordinated tariff adjustment mechanisms in terms of reaching specific national or aggregated deployment target corridors in different scenarios.

Moreover, the model can be used to analyse the impact of different regional or international shocks on deployment effectiveness of coordinated remuneration schemes. For this purpose, we introduce unobserved random variables to represent shocks in behaviour equations. The following equations specify the case that national deployment is subject to a random variable with opposed impact in two countries.

$$
\begin{aligned}
& D_{j t}^{\prime}=D_{j t}+\varepsilon_{t} \\
& D_{k t}^{\prime}=D_{k t}-\varepsilon_{t}
\end{aligned}
$$

This can be the case if there is a fixed number of installers which are mobile across two neighbouring countries. 


\section{Data, parameter choices, and calibration}

The model for the impact of coordinated PV tariff setting was calibrated based on the experience with PV in Germany and the UK. Germany is the largest PV market in the world, and the UK has been the largest PV market in Europe in 2014 (REN21, 2015). Data transparency largely differs across EU Member States, with many countries providing only limited data on aggregated levels. Several of these countries have only limited experience with PV deployment. Therefore, the model is not calibrated to reflect the specific situation of each EU Member State. Instead, the objective is to capture the main drivers that are relevant for the coordination of tariffs between countries.

Germany provides system-specific PV installations data since 2009 (Bundesnetzagentur 2015), while the UK provides weekly PV deployment data for systems up to $50 \mathrm{~kW}$ between February 2012 and March 2014 (DECC 2014a). Therefore, a period $t$ here corresponds to one week. Figure 2 shows weekly deployment of PV systems up to $50 \mathrm{~kW}$ and corresponding feed-in tariff levels in Germany and the UK between February 2012 and March 2014.

Figures 6 and 7 show weekly PV deployment of systems up to $50 \mathrm{~kW}$ and corresponding profit margins for investors in Germany and the UK. Specific shares of these margins are needed to cover project development costs and risks during project lifetime. Profit levels are calculated as net present value, taking into account the present value of the feed-in tariff and the system price of the project. For PV capacity utilisation, we use 1100 full load hours per year for Germany and 1000 full load hours per year for the UK (Philipps et al., 2014). Feed-in tariffs are paid for 20 years, and we assume a 3\% annual interest rate. We use weekly system prices for PV installations up to $50 \mathrm{~kW}$ in Germany and the UK (Figure 4).

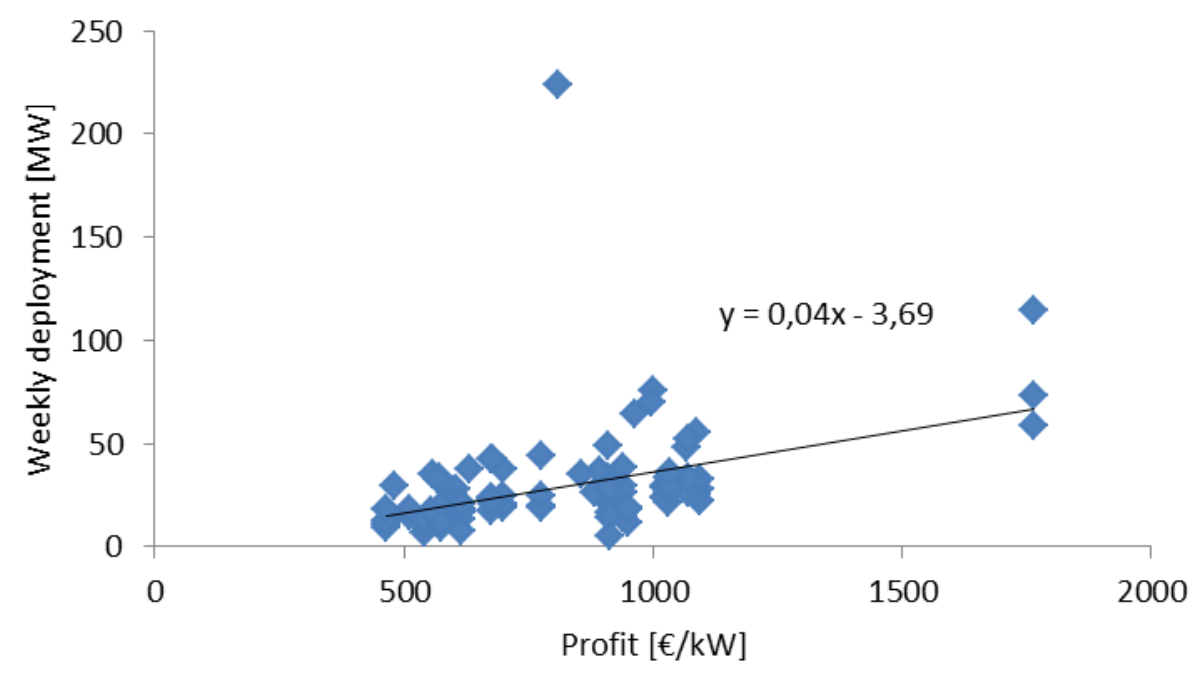

Figure 6: Weekly PV installations and profit levels for systems up to $50 \mathrm{~kW}$ in Germany between March 2012 and March 2014 


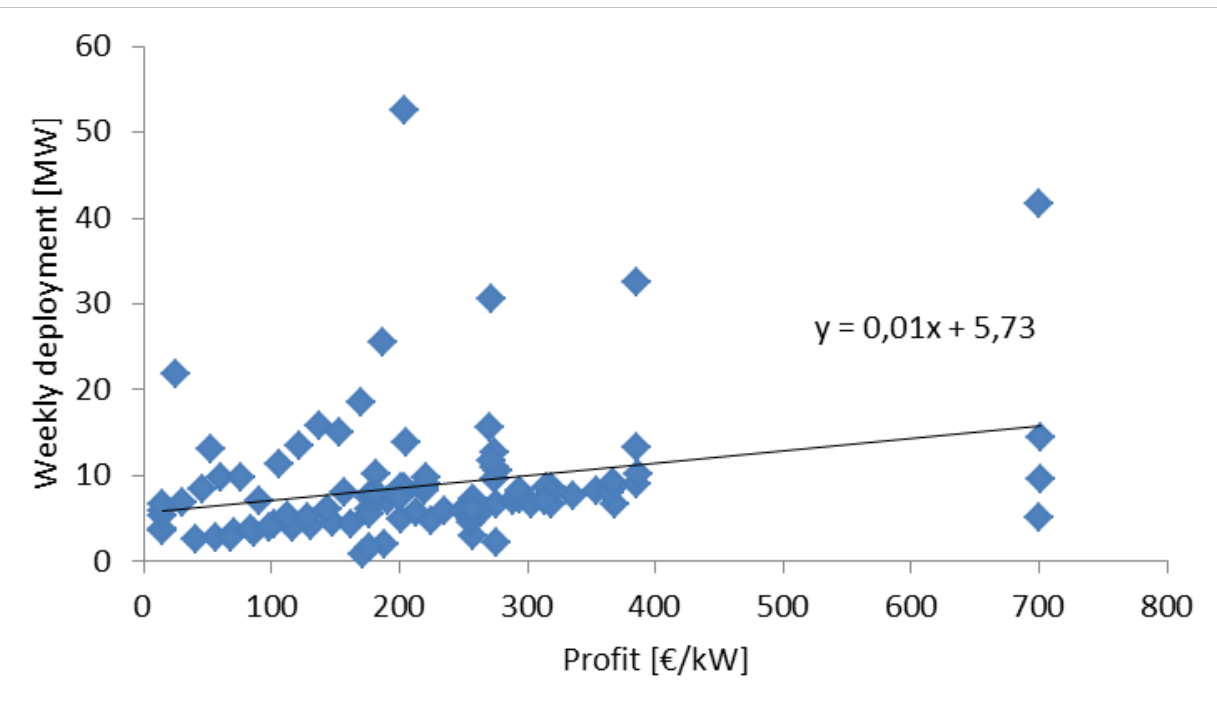

Figure 7: Weekly PV installations and profit levels for systems up to $50 \mathrm{~kW}$ in the UK between March 2012 and March 2014

In both Germany and the UK, installations increase with margins. Quantitative estimations for the period between March 2012 and March 2014 lead to the parameters $\alpha_{D E}=0.04$ and $\alpha_{0, D E}=-3.7$ as well as $\alpha_{U K}=0.01$ and $\alpha_{0, U K}=5.7$. We assume that these correlations between weekly deployment and profit levels stay constant.

For PV module prices in Germany and the UK, we use average prices of crystalline modules from Germany and China on the European spot market (Figure 5). National installation prices are calculated as difference between national system prices and global module prices.

To calibrate the coordinated feed-in tariff setting mechanism which incorporates information on foreign deployment, we consider the responsive feed-in tariff adjustment mechanism in Germany as a base case. Within the German policy scheme, tariffs are automatically adjusted on a monthly scale based on historic national deployment levels. 


\begin{tabular}{|c|c|}
\hline $\begin{array}{c}\text { Deployment } \\
\text { yearly [GW] }\end{array}$ & $\begin{array}{c}\text { Degression } \\
\text { monthly }\end{array}$ \\
\hline$>7.5$ & $2.8 \%$ \\
\hline $6.5<\mathrm{D}<=7.5$ & $2.5 \%$ \\
\hline $5.5<\mathrm{D}<=6.5$ & $2.2 \%$ \\
\hline $4.5<\mathrm{D}<=5.5$ & $1.8 \%$ \\
\hline $3.5<\mathrm{D}<=4.5$ & $1.4 \%$ \\
\hline $2.6<\mathrm{D}<=3.5$ & $1 \%$ \\
\hline $2.4<=\mathrm{D}<=2.6$ & $0.5 \%$ \\
\hline $1.5<=\mathrm{D}<2.4$ & $0.25 \%$ \\
\hline $1.0<=\mathrm{D}<1.5$ & $0 \%$ \\
\hline$<1.0$ & $\mathrm{q} 1.5 \%$ up \\
\hline
\end{tabular}

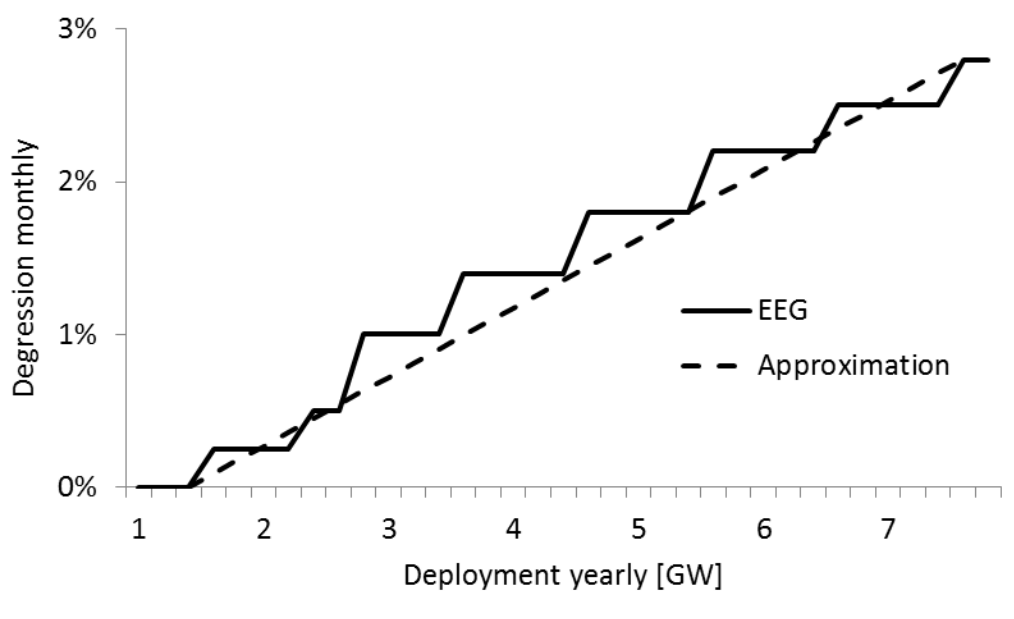

Figure 8: German PV feed-in tariff adjustment mechanism

Figure 8 shows the responsive German PV feed-in tariff adjustment mechanism according to the Renewable Energy Sources Act (EEG 2014). The monthly degression level of the feed-in tariff for new installations depends on historic annual deployment volumes. The target corridor for the deployment of PV installations in Germany amounts to between 2400 MW and 2600 MW per year, with a corresponding basic monthly $0.5 \%$ feed-in tariff degression level. The degression increases with historic installations, up to a $2.8 \%$ degression level if annual deployment exceeds $7.5 \mathrm{GW}$, and can decrease similarly. The dashed line approximates this tariff adjustment scheme to a linear functional form.

For the purpose of our model, we use a weekly tariff adjustment frequency and a sliding quarterly qualification period. Thus, we transfer the base case feed-in tariff adjustment mechanism (Figure 8) from a monthly to a weekly tariff adjustment frequency, and from a yearly to a quarterly qualification period. By linearly approximating degression levels (equation 8), we get the parameters $\beta_{1}=0.014$ (slope of degression line) and $\beta_{0}=-0.002$. Separate and coordinated national tariffs in Germany and the UK are automatically adjusted based on national or international deployment in both countries in the respective previous quarter. 


\section{$5 \quad$ Model results}

The calibrated model can be used to measure the impact of separate and coordinated feed-in tariff adjustment mechanisms on deployment effectiveness in terms of reaching national or aggregated deployment target corridors for different scenarios. We focus our analysis on the impact of different global PV module supply functions, different national installation price reductions, and specific shocks (section 5.1). Based on the results, we discuss the relevance of the insights applicable to wind energy technologies (section 5.2).

\subsection{Simulation results for different scenarios}

We use the calibrated model to simulate PV deployment and different responsive feed-in tariff adjustment mechanisms between April 2014 and March 2017 for different scenarios. To analyse the impact of different global module supply functions and different national installation prices, Table 2 defines scenarios which differ by supply function parameter s (slope, see equation 4 ) and installation price reduction. We neglect the parameter $\mathrm{s}_{0}$ here (we assume a supply function line through origin).

Table 2: Model scenarios

\begin{tabular}{lll}
\hline Scenario & $\begin{array}{l}\text { Supply function } \\
\text { parameter s }\end{array}$ & $\begin{array}{l}\text { Yearly installation price } \\
\text { reduction }\end{array}$ \\
\hline Reference (S1) & 0.05 & $7 \%$ \\
\hline Low slope (S2) & 0.04 & $7 \%$ \\
\hline High slope (S3) & 0.06 & $7 \%$ \\
\hline Strong BOS price red. (S4) & 0.05 & $8 \%$ \\
\hline Weak BOS price red. (S5) & 0.05 & $4 \%$ \\
\hline
\end{tabular}

The yearly target corridor of between $2.4 \mathrm{GW}$ and $2.6 \mathrm{GW}$ in Germany corresponds to a weekly target corridor of between $46 \mathrm{MW}$ and $50 \mathrm{MW}$ across system sizes. PV systems up to $50 \mathrm{~kW}$ represent a $29.7 \%$ market share in Germany between February 2012 and March 2014. This translates into a corresponding target corridor between 13.70 and 14.85 MW per week for systems up to $50 \mathrm{~kW}$. We assume the same target corridor for the UK. Therefore, the aggregated target corridor for both Germany and the UK ranges between 27.4 and 29.7 MW per week for systems up to $50 \mathrm{~kW}$. The light grey horizontal lines in the following figures indicate the respective target corridors.

Figure 9 shows simulated aggregated PV deployment in both Germany and the UK for separate and coordinated tariff adjustment schemes in the reference scenario. The parameters in the reference scenario are chosen in such a way that simulated aggregate deployment starts within the aggregate target corridor at the beginning of the simulation period. While the separate tariff adjustment mechanism takes into account only national deployment of the previous quarter, the coordinated scheme incorporates both German and UK historic deployment. Both tariff mechanisms are able to keep aggregate deployment within the aggregate target corridor (Figure 9). While the coordinated scheme here results in slightly increasing aggregate deployment, separate tariff mechanisms result in slightly decreasing aggregate deployment - this result can be understood by looking at national deployment volumes (see Figure 10). 


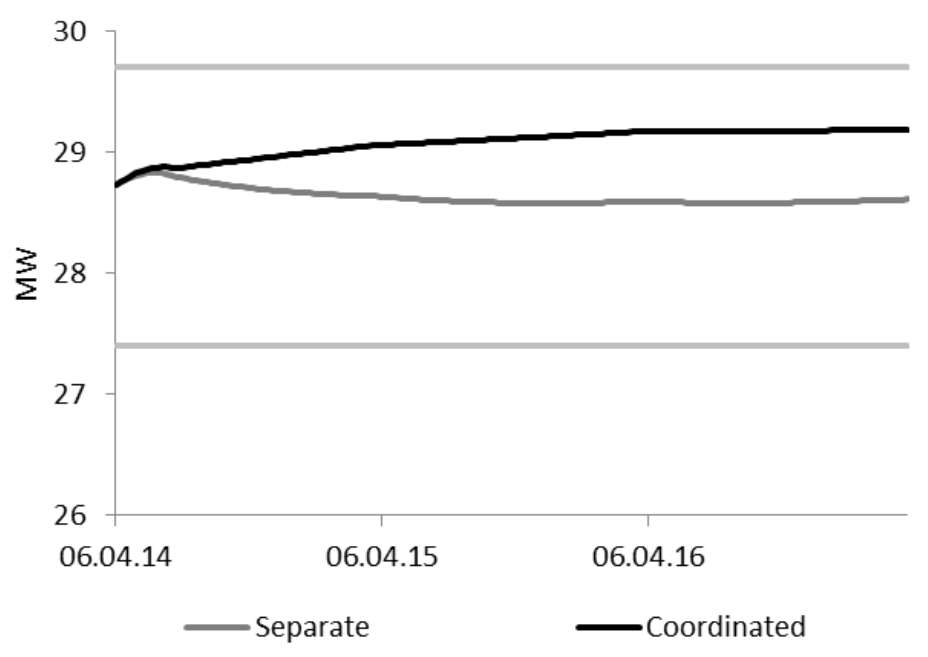

Figure 9: Simulated weekly aggregated deployment of PV systems up to $50 \mathrm{~kW}$ for separate and coordinated tariff adjustment mechanisms in Germany and the UK in the reference scenario

At the beginning of the simulation period, the model calculates that German deployment starts above the target corridor while UK deployment starts below. We observe that separate national tariff adjustment schemes are able to guide national deployment relatively quickly back to the respective national target corridor. In contrast, with the coordinated tariff mechanism applying the same adjustment factor to German and UK tariffs, resulting national deployment only gradually converges towards the national corridor (Figure 10). For PV systems up to $50 \mathrm{~kW}$ in Germany and the UK, around two thirds of the total system prices are determined by elements other than globally traded PV module prices; therefore the adjustment to deviations that might be country specific is apparently more important than the adjustment to the global (PV module) price trend.

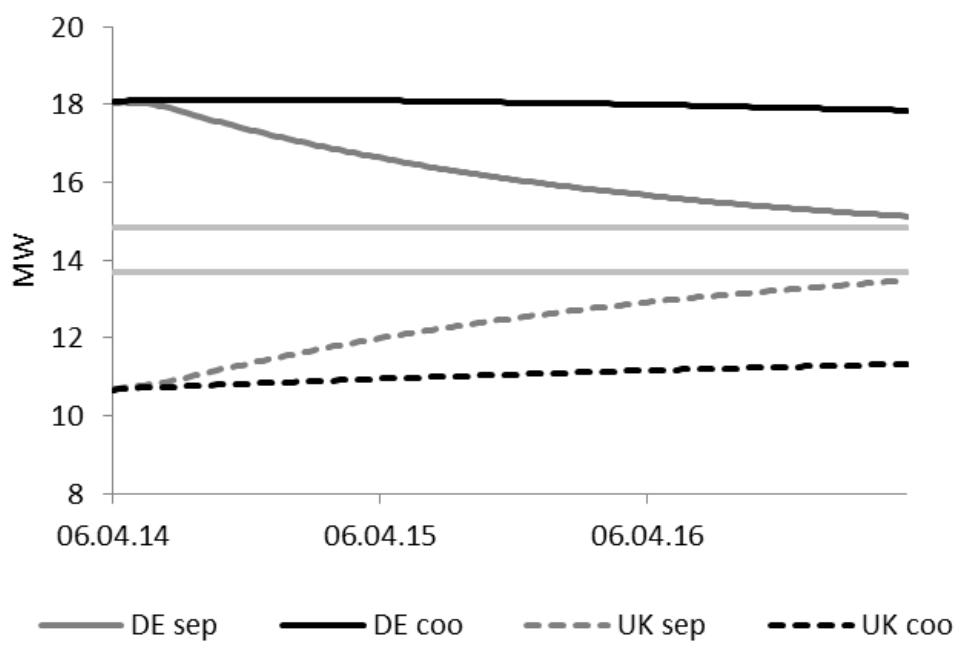

Figure 10: Simulated weekly national deployment of systems up to $50 \mathrm{~kW}$ for separate and coordinated tariff adjustment mechanisms in Germany and the UK in the reference scenario 
Figure 11 shows specific examples to illustrate that this generic statement may not apply in specific instances. The figure shows simulated weekly aggregated installations of systems up to $50 \mathrm{~kW}$ in both countries for separate and coordinated tariff mechanisms in the 'Low slope' and 'High slope' scenarios. If aggregate deployment at the beginning of the simulation period starts below target levels, coordinated tariff mechanisms are more effective in terms of reaching the aggregate corridor again - in this case all countries require the same direction of adjustment and the joint adjustment ensures a stronger response also in Germany driven by the large deviation caused from the UK. However, if aggregate deployment starts above corridor, separate tariff mechanisms are more effective.
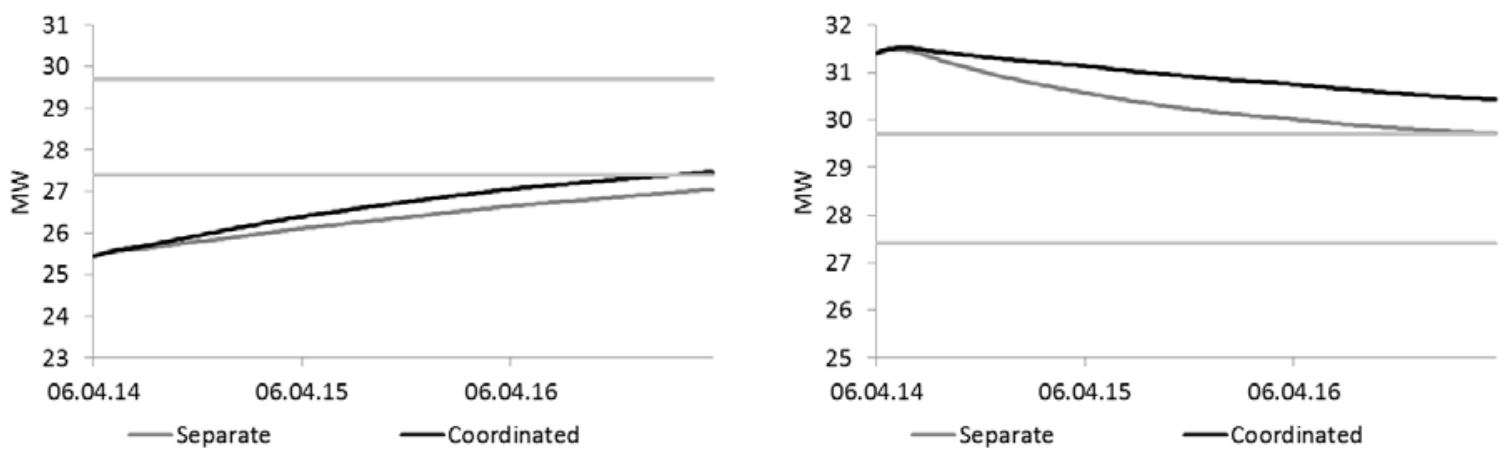

Figure 11: Simulated aggregated installations for separate and coordinated tariff mechanisms in the 'Low slope' scenario (left) and the 'High slope' scenario (right)

Figure 12 shows simulated aggregated deployment of systems up to $50 \mathrm{~kW}$ in the 'Strong BOS price red.' and 'Weak BOS price red.' scenarios. In the scenario with of stronger installation price reductions, separate adjustment schemes are more effective in keeping deployment within the target corridor, while the coordinated tariff mechanism is more effective in the scenario with a weaker price reductions.
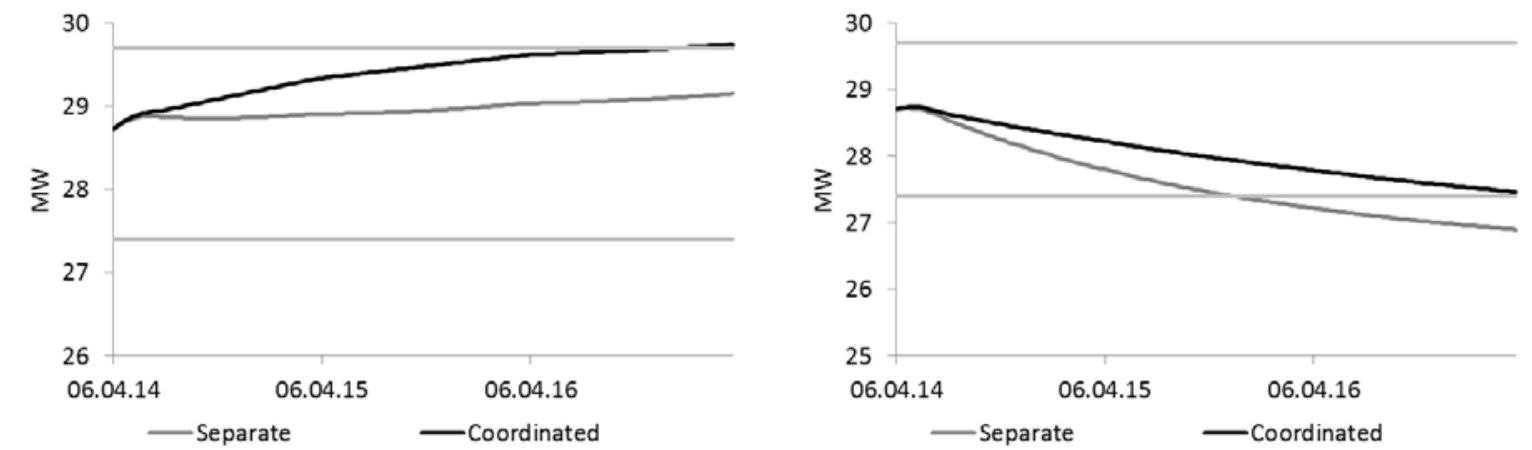

Figure 12: Simulated aggregated deployment for separate and coordinated tariff mechanisms in the 'Strong BOS price red.' scenario (left) and the 'Weak BOS price red.' scenario (right) 
These model results are in line with a set of hypothesis: If countries have different asymmetric response rates between deployment and profit margins (see for instance Figures 6 and 7), separate tariff adjustment mechanisms are more effective for national corridor achievement than coordinated schemes. However, it is possible to identify specific scenarios in which coordinated tariff adjustment can be more effective concerning aggregate corridor achievement. This leads to the question if for specific circumstances coordination could also be more effective from a national corridor perspective? Given that the idea of coordination is to gather as much new information as possible, specific market shocks might affect the performance of support schemes.

In the following, we use the model to measure the impact of specific shocks on deployment effectiveness of separate and coordinated tariff mechanisms. In particular, we focus on random shocks with opposed effects in neighbouring countries, which might happen in case of sudden policy changes and if there is a limited number of installers which are mobile across countries (see equations 10 and 11). In the 'deployment shock' scenario, partial historic deployment volumes of $9 \mathrm{MW}$ per week shift from Germany to the UK during February and March 2014. Apart from this shock, parameters are set as given in the reference scenario.

Figure 13 shows corresponding simulation results. Coordinated tariffs are set based on aggregate historic deployment across countries (see equation 9), and therefore lead to the same aggregate and national deployment volumes as in the reference scenario. However, for this scenario, the separate adjustment mechanism in the short term is less effective than the coordinated scheme with regard to reaching national corridors. Even though national deployment in Germany starts above the target corridor at the beginning of the simulation period, the separate tariff mechanism leads to more national deployment in Germany between April and August 2014 than the coordinated scheme. This is because at the beginning of the simulation period profit margins in Germany for the separate case first increase relatively strongly due to quickly increasing feed-in tariffs (resulting from the adjustment mechanism taking into account historic deployment of the previous quarter, which is affected by the deployment shock). We observe a similar effect for the UK, with opposed direction.
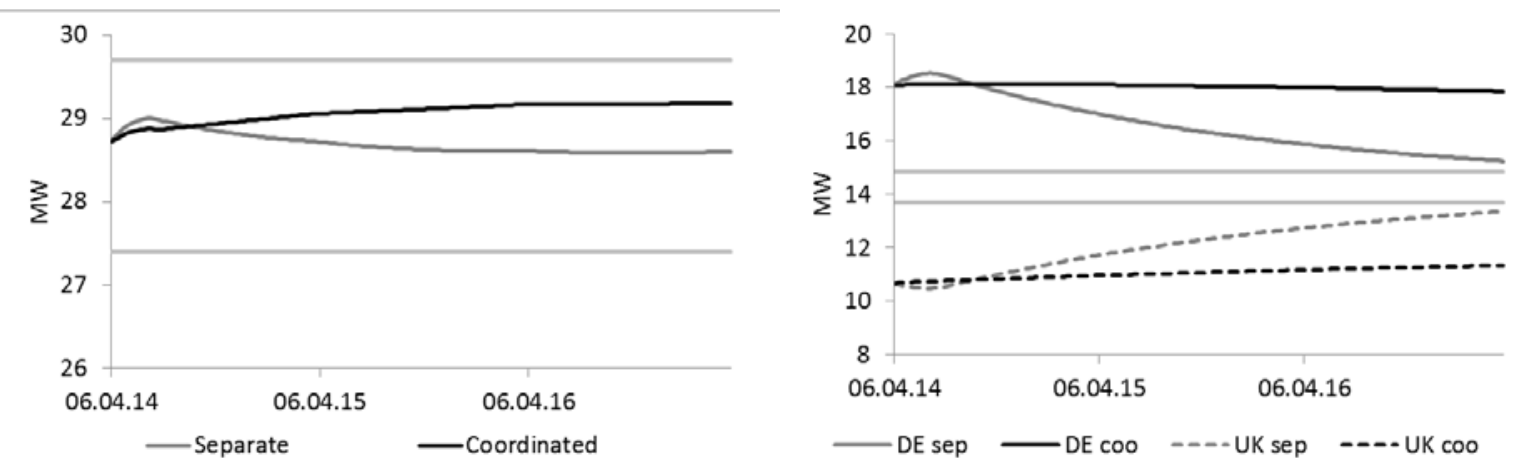

Figure 13: Simulated aggregated (left) and national (right) deployment for separate and coordinated tariff mechanisms in the 'deployment shock' scenario 
While separate tariff adjustment mechanisms are generally more effective in guiding national deployment towards target corridors, coordination might result for some specific deployment shocks in better responses. However, in case of deployment shocks with converse direction (partial deployment shifting from the UK to Germany), separate schemes remain more effective also in the short term. In this regard it is important to note that, if such shocks are more permanent, specific ad hoc tariff adjustments might be helpful to correct the mechanism for unexpected occasions.

Model results show that separate support schemes are more effective in reaching national target corridors, if countries have different response rates between deployment and profit margins. However, this may not always apply in the case of shocks. We identified specific market shocks for which coordinated tariff adjustment can improve target achievement in the short-term.

\subsection{Insights applicable to wind energy technologies}

Some of the insights which emerged are also applicable to wind electricity technologies. In this section, we compare the underlying market characteristics of PV and wind technologies, to qualitatively assess the options and relevance of applying the respective insights to wind onshore energy.

Wind turbines have shown less dynamic cost reductions in comparison to PV modules. While PV module prices declined by around 75\% between 2009 and 2014, wind turbine prices decreased by only around 30\% in developed countries (IRENA 2015b). This means that a coordinated tariff adjustment mechanism for wind energy can potentially be calibrated on lower frequency data (e.g. monthly instead of weekly data) and use a lower tariff adjustment frequency.

PV panels have no moving parts, they require less monitoring and maintenance in comparison to wind farms. While there are no variable operation and maintenance cost for PV, they can be significant for wind onshore (IPCC 2014). Therefore, O\&M cost should be taken into account when designing coordinated tariff mechanisms for wind energy.

While PV modules tend to be global commodities with similar prices across countries, wind turbines are tailored more to local climatic conditions. This also allows producers to differentiate prices across countries (IRENA 2015b). Thus the focus of coordinating tariff adjustment mechanisms for wind energy is less on enhancing target achievement and more linked to realizing additional information opportunities to strengthen the level of global competition and thus contribute to cost reductions.

Wind projects have longer project development and construction durations than PV installations. PV systems can be relatively easy and quickly installed particularly on rooftops, which makes their deployment strongly responsive to changes in remuneration levels, module or installation prices. Wind projects face longer and more complex administrative procedures and more administrative barriers (permits, grid connection, etc.). The responsiveness of wind energy deployment to changes in profit levels is relatively limited. A coordinated tariff mechanism for wind energy should therefore 
account for longer project durations and the corresponding responsiveness of deployment to profitability levels.

Similar to PV, if countries have different asymmetric response rates between deployment and profit margins, coordinated tariff mechanisms for wind energy seem to be useful rather for the achievement of aggregate than for national target corridors. 


\section{Conclusion}

The dynamics of the global PV market has often resulted in unexpected high deployment volumes in EU Member States. Feed-in tariffs are a common policy instrument in Europe to remunerate renewable electricity generation, but pose the challenge of setting remuneration levels which are appropriately aligned with technological cost reductions. Coordinated tariff adjustment mechanisms might help to improve deployment effectiveness in terms of reaching specific target corridors. With the perspective of increased coordination of tariff mechanisms across EU Member States, coordinated schemes have to take into account the global nature of PV module prices.

This paper develops an analytic model to capture the interactions of national support schemes with the global market, in order to provide insights on the impact of coordinated remuneration schemes for renewable energies across EU Member States. The model allows for the analysis of different options to coordinate feed-in tariffs and their relative benefits. Harmonised tariff adjustment mechanisms with equal remuneration levels across countries seem not to be a feasible option because of different national market conditions and information asymmetries. We therefore focus on the coordination of feedin tariffs through information exchange between countries, with a particular focus on exchanging information on deployment levels.

The model is calibrated based on the experience with PV in selected Member States, namely Germany, which is the largest PV market in the world, and the UK, which has been the largest PV market in Europe in 2014. Coordination could also take the form of information exchange between countries in the process of calibrating a separate or corporate remuneration adjustment scheme. Such coordination might support in particular countries with less experience in a specific technology in setting appropriate tariff levels.

We use the model to simulate PV deployment for separate and coordinated tariff adjustment mechanisms under different scenarios. Simulation results show that separate schemes are more effective than coordinated mechanisms in reaching national deployment target corridors, if countries have different asymmetric response rates between deployment and profit margins. However, for specific supply functions and installation price scenarios a coordinated scheme with identical tariff adjustment factors may be more effective in terms of reaching aggregate deployment target corridors.

This inferior performance of the coordinated tariff adjustment is in particular of interest, because it mimics in many ways internationally integrated market premium or tradable certificate systems (e.g. harmonisation of premium or certificate trade). The analysis identifies one challenge that needs to be considered with such mechanisms. The adjustment might not respond effectively to drivers at national level like administrative requirements or system integration costs that could dominate the overall effect. However, to the extent that such national drivers reflect market power mark-ups, a joint response increases the market scale and thus enhances competitiveness of prices.

The model can be used to analyse the impact of different shocks on deployment effectiveness of separate and coordinated tariff adjustment mechanisms. Simulation results show that separate schemes remain more effective than coordinated mechanisms 
with regard to reaching national target corridors in the long term. However, coordinated remuneration schemes might have specific positive effects in case of market shocks. In the short term, coordination can be more effective concerning national corridor achievement for specific temporary deployment shocks with opposed effects in neighbouring countries. Overall, effective coordinated schemes should enable specific ad hoc tariff adjustments in case of extreme or permanent market shocks.

The model framework in this report assumes linear demand and supply functions. Approaches with other functional forms can result in different response rates of national or coordinated tariff adjustment mechanisms with regard to exogenous market shocks. Coordinated remuneration schemes may also help to reduce incentives for strategic gaming. This can happen in small countries if incumbent companies or large projects withhold installations to increase prices.

Wind energy technologies have different market characteristics in comparison to PV, like less dynamic cost reductions, large technology price differences across countries, larger operation and maintenance cost, and longer project development durations. This means that a coordinated tariff adjustment mechanism for wind energy can be calibrated on lower frequency data, should account for operation and maintenance cost, can use a lower tariff adjustment frequency, could consider exogenous system price developments, and should account for longer project durations and the corresponding responsiveness of deployment. 


\section{References}

Bundesnetzagentur (2015). Datenmeldungen und EEG-Vergütungssätze für Photovoltaikanlagen.

http: //www. bundesnetzagentur.de/cln_1431/DE/Sachgebiete/ElektrizitaetundGas/Un ternehmen_Institutionen/ErneuerbareEnergien/Photovoltaik/Photovoltaik_node.html (retrieved 3 July 2015).

DECC (2012). Solar PV cost update. Department of Energy \& Climate Change. Prepared by Parsons Brinckerhoff.

DECC (2014a). Weekly solar PV installation \& capacity based on registration date. Statistical data set. Department of Energy \& Climate Change.

DECC (2014b). Solar PV cost data. Department of Energy \& Climate Change.

EC (2014). Guidelines on State aid for environmental protection and energy 2014-2020 (2014/C 200/01). European Commission.

EEG (2014). Gesetz für den Ausbau erneuerbarer Energien (Erneuerbare-EnergienGesetz).

EU Directive (2009). Directive 2009/28/EC of the European Parliament and of the Council of 23 April 2009 on the promotion of the use of energy from renewable sources and amending and subsequently repealing Directives 2001/77/EC and 2003/30/EC.

Official J ournal of the European Union.

Fh ISE (2015). Current and Future Cost of Photovoltaics. Long-term Scenarios for Market Development, System Prices and LCOE of Utility-Scale PV Systems. Study on behalf of Agora Energiewende. Fraunhofer ISE.

Grau, T. (2014). Responsive feed-in tariff adjustment to dynamic technology development. Energy Economics, Volume 44, Pages 36-46.

Held, A., M. Ragwitz, M. Gephart, C. Kleßmann, E. de Visser (2014). DiaCore D5.2: Best practice design features for RES-E support schemes and best practice methodologies to determine remuneration levels. Fraunhofer ISI.

IEA (2011). IEA PVPS National Survey Report of PV Power Applications in Germany 2010. International Energy Agency.

IEA (2014). Technology Roadmap Solar Photovoltaic Energy. International Energy Agency.

IPCC (2014). Schlömer S., T. Bruckner, L. Fulton, E. Hertwich, A. McKinnon, D. Perczyk, J. Roy, R. Schaeffer, R. Sims, P. Smith, and R. Wiser. Annex III: Technology-specific cost and performance parameters. In: Climate Change 2014: Mitigation of Climate Change. Contribution of Working Group III to the Fifth Assessment Report of the Intergovernmental Panel on Climate Change [Edenhofer, O., R. Pichs-Madruga, Y. Sokona, E. Farahani, S. Kadner, K. Seyboth, A. Adler, I. Baum, S. Brunner, P. Eickemeier, B. Kriemann, J. Savolainen, S. Schlömer, C. von Stechow, T. Zwickel and J.C. Minx (eds.) ]. Cambridge University Press, Cambridge, United Kingdom and New York, NY, USA. 
IRENA (2015a). Renewable Energy Capacity Statistics 2015. International Renewable Energy Agency.

IRENA (2015b). Renewable power generation costs in 2014. International Renewable Energy Agency.

Kitzing, L., C. Mitchell, P.E. Morthorst (2012). Renewable energy policies in Europe: Converging or diverging?. Energy Policy 51 (2012) 192-201.

Klessmann, C., E. de Visser, F. Wigand, M. Gephart, G. Resch, S. Busch (2014). Cooperation between EU Member States under the RES Directive. Task 1 report. Ecofys.

Lehmann, P., F. Creutzig, M.-H. Ehlers, N. Friedrichsen, C. Heuson, L. Hirth, R. Pietzcker (2012). Carbon Lock-Out: Advancing Renewable Energy Policy in Europe. Energies 2012, 5, 323-354.

Ofgem (2014). Feed-in Tariff Payment Rate Table for Photovoltaic Eligible Installations.

Philipps, S.P., C. Kost, T. Schlegl (2014). Up-to-date levelised cost of electricity of photovoltaics. Fraunhofer ISE.

Photovoltaik-guide (2014). Photovoltaik-Preisindex. www.photovoltaik-guide.de/pvpreisindex.

PvXchange (2015). Preisindex Großhandelspreise kristalline Solarmodule. www. pvxchange.com (retrieved 3 August 2015).

REN21 (2015). Renewables 2015 Global Status Report (Paris: REN21 Secretariat).

Seel, J., G.L. Barbose, R.H. Wiser (2014). An analysis of residential PV system price differences between the United States and Germany. Energy Policy, Volume 69, Pages 216-226. 